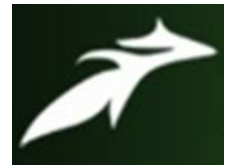

Anil Kanaujia et al, International Journal of Advances in Agricultural Science and Technology,

Vol.8 Issue.6, June-2021, pg. 1-9

ISSN: 2348-1358

Impact Factor: 6.057

NAAS Rating: 3.77

\title{
SOIL HEALTH STATUS OF SELECT VILLAGE OF DISTRICT SONIPAT, HARYANA AND WAY FORWARD
}

\section{Anil Kanaujia ${ }^{1}$; Samanwita Banerjee ${ }^{2 *}$; Suruchi Malik ${ }^{3}$; Kirti Sharma ${ }^{4}$; Deepak Tyagi ${ }^{5}$; Deepti Rai ${ }^{6}$; Abha Saxena}

\author{
${ }^{1}$ Head R\&D, ank@arfmail.in \\ ${ }^{2}$ Microbiologist, samanwita.banerjee@ arfmail.in \\ ${ }^{3}$ Microbiologist, suruchi.mallik@arfmail.in \\ ${ }^{4}$ Analyst, kirti.sharma@ arfmail.in \\ ${ }^{5}$ Executive, dtyagi@arfmail.in \\ ${ }^{6}$ Principal Scientist, drai@arfmail.in \\ ${ }^{7}$ Executive, abha.saxena@arfmail.in \\ DOI: 10.47856/ijaast.2021.v08i6.001
}

\begin{abstract}
Soil health and fertility are the basis for gaining sustainable profit through higher productivity by the farmers. Using optimal doses of fertilizers and cropping pattern as per the scientific recommendations is the first step towards sustainable farming. Soil organic carbon (SOC) is the most important component in maintaining soil quality because of its role in improving physical, chemical, and biological properties of the soil. Organic matter is an important source of nitrogen, phosphorus and sulfur. Soil Health card is a Government of India's scheme promoted by the Department of Agriculture \& Co-operation under the Ministry of Agriculture and Farmers' Welfare, apart from giving the health index of soil, will also indicate fertilizer recommendations and soil amendment required for the farm. Under Govt. of Haryana sanctioned Soil Health Card project, ARF carried out the fertility status study of 3000 acres of land of village Baroda Mor, block Mundlana, Tehsil Gohana, Sonipat, Haryana and distribute the cards well before the harvesting of Rabi crop with proper recommendation on dosage of appropriate fertilizer as per deficiency of essential nutrient parameter
\end{abstract}

Keywords: Organic Carbon, STFR, Soil Health Card, Fertility, Replenish.

\section{Introduction}

Soil health is the continued capacity of soil to function as a vital living ecosystem that sustains plants, animals and humans. A healthy soil acts as a dynamic living system that delivers multiple ecosystem services, such as sustaining water quality and plant productivity, controlling soil nutrient recycling decomposition, and removing greenhouse gases from the atmosphere. It is closely associated with sustainable agriculture, because soil microorganism diversity and activity are the main components of soil health.

Plants need an adequate supply of nutrients to grow and complete their reproductive phases. There are 17 nutrient elements that most land plants need for productive growth and development. Elements of concern for soil fertility management are classified into three categories. The first category is called primary nutrients: nitrogen, phosphorus, and potassium. The second category is called secondary nutrients: calcium, magnesium, and sulfur. The third category is called micronutrients: zinc, manganese, boron, copper, chlorine, iron, nickel, 


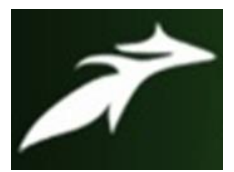

Anil Kanaujia et al, International Journal of Advances in Agricultural Science and Technology,

Vol.8 Issue.6, June-2021, pg. 1-9

ISSN: 2348-1358

Impact Factor: 6.057

NAAS Rating: 3.77

and molybdenum. All these nutrient elements are essential for plants, and the absence of any of them will cause plant disorders and affect plant growth and yield (John Idowu et. al, 2019).

Soil health and fertility are the basis for gaining sustainable profit through higher productivity by the farmers. Using optimal doses of fertilizers and cropping pattern as per the scientific recommendations is the first step towards sustainable farming. Soil organic carbon (SOC) is the most important component in maintaining soil quality because of its role in improving physical, chemical, and biological properties of the soil.

Soil Health card is a Government of India's scheme promoted by the Department of Agriculture \& Cooperation under the Ministry of Agriculture and Farmers' Welfare, being implemented through the Department of Agriculture of all the State and Union Territory Governments. SHC, apart from giving the health index of soil, will also indicate fertilizer recommendations and soil amendment required for the farm (Kanujia. A et. al, 2020).

Ayurvet Research Foundation (ARF) a public charitable trust, undertakes various initiatives for the sustainable integration of livestock and agriculture for the benefit of farmers and society at large. Major interventions of the Organization's are conducting research in the areas of food safety, agriculture, hydroponics, AMR, animal health and nutrition, medicinal plants, soil and water health, waste to wealth management and extension activities like rural development, rural entrepreneurs' development and women empowerment.

In the year 2020, Govt. of Haryana sanctioned Soil Health Card project to ARF to carry out fertility status study of 3000 acres of land of village Baroda Mor, block Mundlana, tehsil Gohana, Sonipat, Haryana and distribute the cards well before the harvesting of Rabi crop in year 2021. Team ARF systematically carried out the registration of farmers, collection of 3000 soil samples, analysis for 12 parameters namely N, P, K (Macronutrients); S (Secondary- nutrient); Zn, Fe, Cu, Mn, B (Micro - nutrients); and pH, EC, OC (Physical parameters), fertilizer recommendation and distribution of cards..

\section{MATERIALS AND METHODS}

Soil Samples were collected by trained team from a depth of $15-20 \mathrm{~cm}$ by cutting the soil in a "V" shape, from four corners and the center of the field and mixed thoroughly to make a sample, coded and transferred to laboratory. GPS system was used to lock the longitude and latitude position of each acre of land from where the sample was collected. Samples were properly stored in racks for traceability, registered on portal before taken up for analysis (Fig: 2).

\subsection{PROCESSING OF SOIL SAMPLES}

Air-dried the soil samples in shade, discarded the plant residues, gravels and other materials, crushed the soil lumps lightly and grounded with the help of mechanical pulverizer, passed the entire quantity through a $2 \mathrm{~mm}$ stainless steel sieve, for organic carbon grounded the soil further so as to pass it through 0.2 to $0.5 \mathrm{~mm}$ sieves, remixed the entire quantity of sieved soil thoroughly before analysis ( Fig: 1).

\subsection{METHODOLOGY}

\subsection{1 pH (acidity or alkalinity)}

Calibrated the instrument with pH buffers 4,7 and 9 . Took $10 \mathrm{~mL}(12 \mathrm{~g})$ soil with a syringe in a glass beaker and added $24 \mathrm{ml}$ distilled water. Stirred the suspension for 2 minutes and then measured the $\mathrm{pH}$ by dipping $\mathrm{pH}$ electrode in soil suspension (STFR Manual). 


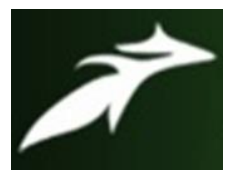

Anil Kanaujia et al, International Journal of Advances in Agricultural Science and Technology,

Vol.8 Issue.6, June-2021, pg. 1-9

ISSN: 2348-1358

Impact Factor: 6.057

NAAS Rating: 3.77

\subsubsection{Electrical Conductivity}

Calibrated the instrument with standard solution. Took $10 \mathrm{~mL}(12 \mathrm{~g})$ soil with a syringe in a glass beaker and added $24 \mathrm{ml}$ distilled water. Stirred the suspension for 2 minutes and then measured the EC by dipping EC electrode in soil suspension (STFR Manual).

\subsubsection{Organic Carbon and Nitrogen}

Took twenty-one glass beakers (100 ml, each) and marked them as B (for blank) and 1-20 for samples. Added 11 drops of distilled water in blank beaker and $0.4 \mathrm{ml}$ of respective soil samples in marked beakers. Added reagents in all the beakers and kept undisturbed for $1 / 2 \mathrm{hr}$. Added $47 \mathrm{ml}$ distilled water with the help of $50 \mathrm{ml}$ measuring cylinder to all the beakers and mixed them with a glass rod. Took another set of glass beaker and filtered the sample solutions. Took the readings of the blank solution first and then one by one of the sample solutions using cuvette on STFR machine which automatically calculates the amount of Organic carbon present in each sample. Calculated available Nitrogen from organic carbon content of soil (STFR Manual).

\subsubsection{Phosphorus (P)}

Took twenty-one wide mouth shaking bottles and marked them as PB for blank and P1 - P20 for samples. Took $0.5 \mathrm{ml}(0.6 \mathrm{~g})$ soil from each of twenty samples by the syringe and transferred into the respectively marked bottles. Added $12 \mathrm{ml}$ of extractant plus $0.3 \mathrm{ml}$ charcoal with the help of syringe to each, closed the caps. Put all the bottles in the shaker for half an hour. Took twenty-one distilled water washed $50 \mathrm{ml}$ dropping bottles with plastic funnels and filter paper, marked them as PB, P1 - P20. Filtered the contents into the P dropping bottles.

Colour Development: Took 21 disposable $15 \mathrm{ml}$ tubes washed with distilled water, marked them as PB (for blank), P1- P20 (for samples) and put them on test tube stand. For Blank: Took $2 \mathrm{~mL}$ filtered blank solution in the test tube marked as PB with the help of $2 \mathrm{ml}$ syringe.

For Samples: Took $2 \mathrm{~mL}$ filtered sample solution in each of the sample test tube from respective dropping bottles marked as P1 - P20 with the help of $2 \mathrm{ml}$ syringe. Washed the syringe with distilled water before each addition. Added reagents with $55 \mathrm{~mL}$ syringe in all test tubes, added distilled water up to mark, vortexed and waited for 15 minutes. Took the reading of blank and samples using cuvette on STFR machine which automatically calculates the amount of phosphorus present in each sample (STFR Manual).

\subsubsection{Potassium (K)}

Took twenty-one wide mouth shaking bottles and marked them as KB for blank and K1- K20 for samples. Took $2.5 \mathrm{~mL}(3 \mathrm{~g})$ soil from each of twenty samples in well- marked bottles. Added $15 \mathrm{ml}$ of extractant and 0.3 $\mathrm{ml}$ charcoal with the help of syringe to each of the sample bottles as well as blank bottle, closed the cap. Put all the bottles in the shaker for half an hour and filter. Took twenty-one distilled water washed $50 \mathrm{ml}$ dropping bottles with plastic funnels and filter paper, marked them as PB, K1 - K20. Filtered the contents into the K dropping bottles.

For Blank: Took $2 \mathrm{~mL}$ filtered blank solution in the test tube marked as KB from dropping bottle KB with the help of $2 \mathrm{ml}$ syringe

For Samples: Took $1 \mathrm{ml}$ filtered blank solution in each of the sample test tube marked as K1- K20 from dropping bottle KB with the help of $1 \mathrm{ml}$ syringe. Added $1 \mathrm{~mL}$ filtered sample solution in marked sample test tubes from respective marked dropping bottles with the help of $1 \mathrm{ml}$ syringe. Washed the syringe with distilled water before each addition.

For all the test tubes: Added reagents to all the test tubes, vortexed with cap closed. Waited for three minutes, added remaining reagents step wise quickly and water up to $10 \mathrm{~mL}$ mark. Vortexed and waited for 5 minutes. Took the reading of blank and samples using cuvette on STFR machine which automatically calculates the amount of potassium present in each sample. Calibrated the instrument with potassium standard. 


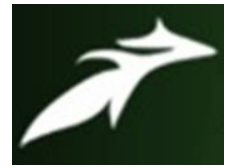

Anil Kanaujia et al, International Journal of Advances in Agricultural Science and Technology,

Vol.8 Issue.6, June-2021, pg. 1-9

Micro nutrients were also analyzed as per procedure described in STFR Manual (3).

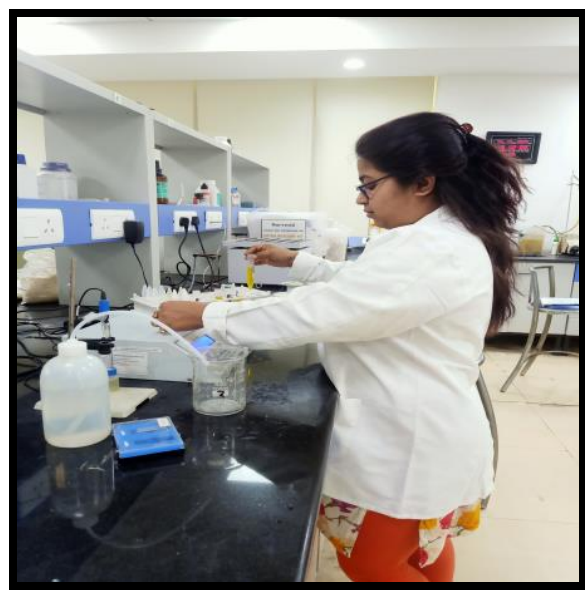

Fig: 1 Analysis of Soil sample using STFR

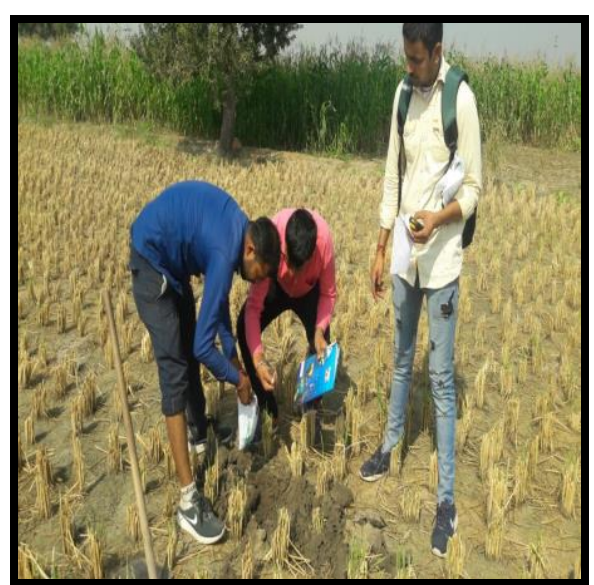

Fig: 2 Collection of soil sample

\section{RESULTS AND DISCUSSION}

Table: 1 Observations of 3000 soil samples analyzed at ARF R\&D center.

\begin{tabular}{|c|l|c|}
\hline Sl. No. & \multicolumn{1}{|c|}{ Parameters } & Range of results \\
\hline $\mathbf{1}$ & $\mathrm{pH}$ & $7.01-8.99$ \\
\hline $\mathbf{2}$ & $\mathrm{EC}(\mathrm{mS} / \mathrm{cm})$ & $0.11-2.00$ \\
\hline $\mathbf{3}$ & $\mathrm{OC}(\%)$ & $0.10-0.45$ \\
\hline $\mathbf{4}$ & $\mathrm{N}(\mathrm{Kg} / \mathrm{ha})$ & $50-227.00$ \\
\hline $\mathbf{5}$ & $\mathrm{P}(\mathrm{Kg} / \mathrm{ha})$ & $2.51-21.26$ \\
\hline $\mathbf{6}$ & $\mathrm{K}(\mathrm{Kg} / \mathrm{ha})$ & $120.60-997.80$ \\
\hline $\mathbf{7}$ & $\mathrm{S}(\mathrm{ppm})$ & $21.42-106.39$ \\
\hline $\mathbf{8}$ & $\mathrm{Zn}(\mathrm{ppm})$ & $0.11-2.03$ \\
\hline $\mathbf{9}$ & $\mathrm{Fe}(\mathrm{ppm})$ & $1.21-10.04$ \\
\hline $\mathbf{1 0}$ & $\mathrm{Mn}(\mathrm{ppm})$ & $1.01-10.08$ \\
\hline $\mathbf{1 1}$ & $\mathrm{Cu}(\mathrm{ppm})$ & $0.12-4.71$ \\
\hline $\mathbf{1 2}$ & $\mathrm{B}(\mathrm{ppm})$ & $0.14-2.07$ \\
\hline
\end{tabular}

3.1 pH: The average $\mathrm{pH}$ was reported to be $\mathbf{7 . 7 \pm 0 . 4}$, which indicates that the soil is Moderately alkaline. Out of 3000 samples $27.87 \%$ (836) were in normal range (6.5-7.5), 65.53\% (1966) were in Moderately alkaline range (7.5-8.5) and 6.6\% (198) were in strongly alkaline range (More than 8.5) (Fig: 3).

3.2 EC: The average EC was reported to be $\mathbf{0 . 6 7 \pm 0 . 0 4}$, which indicates that the soil is Moderately saline and is of low fertility. Out of 3000 samples $71.28 \%(2138)$ are non- saline, $23.83 \%(715)$ are moderately saline and 4.9\%(147) are strongly saline (Fig: 4). 


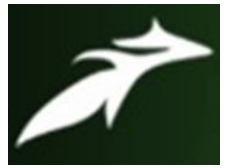

Anil Kanaujia et al, International Journal of Advances in Agricultural Science and Technology,

Vol.8 Issue.6, June-2021, pg. 1-9

ISSN: 2348-1358

Impact Factor: 6.057

NAAS Rating: 3.77

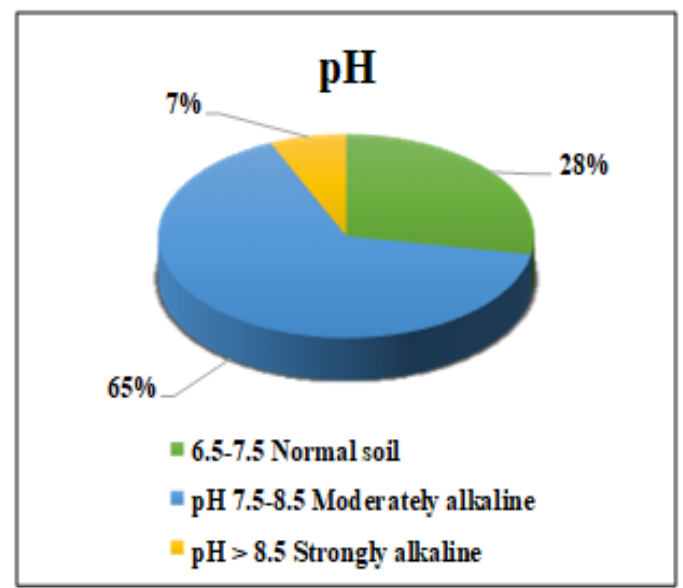

Fig: 3 Graphical representation of $\mathrm{pH}$

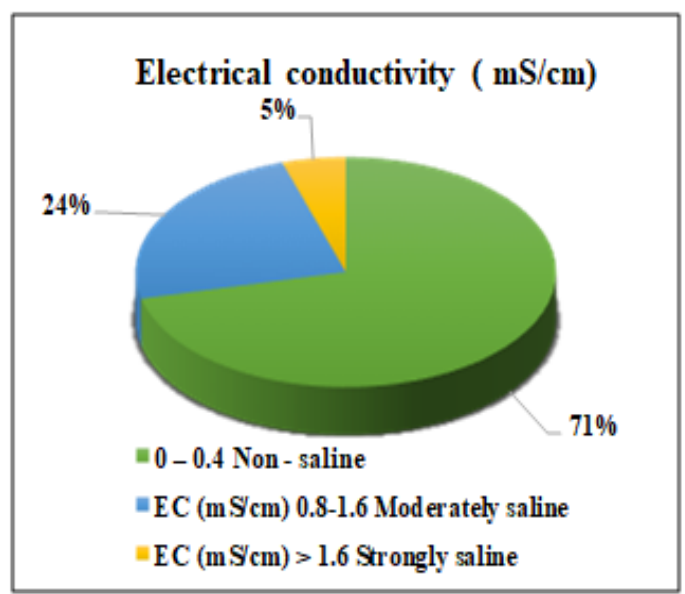

Fig: 4 Graphical representation of EC

3.3 Organic Carbon $(\%, w / w)$ : The average OC $\%$ was reported to be $\mathbf{0 . 3} \mathbf{0 0 . 1}$, which indicates that the soil is very low in fertility and organic content. Out of 3000 samples $78.23 \%$ (2347) have low Carbon content and $21.77 \%$ (653) have medium carbon content. This Point needs special attention as replenishing soil carbon is an important (Fig: 5)

3.4 Nitrogen, $\mathbf{N}(\mathbf{K g} / \mathbf{h a})$ : The average Nitrogen content was reported to be $\mathbf{1 6 1} \pm \mathbf{4 0}$, which indicates soil Nitrogen is low in all the 3000 samples (Fig: 6).

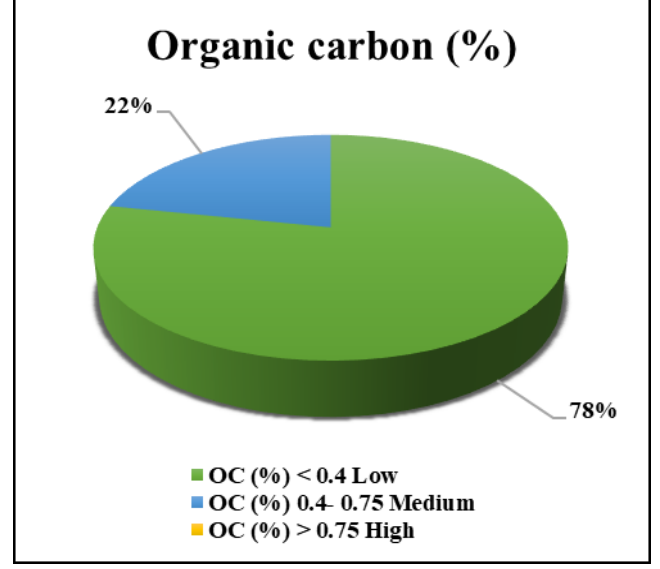

Fig: 5 Graphical representation of OC

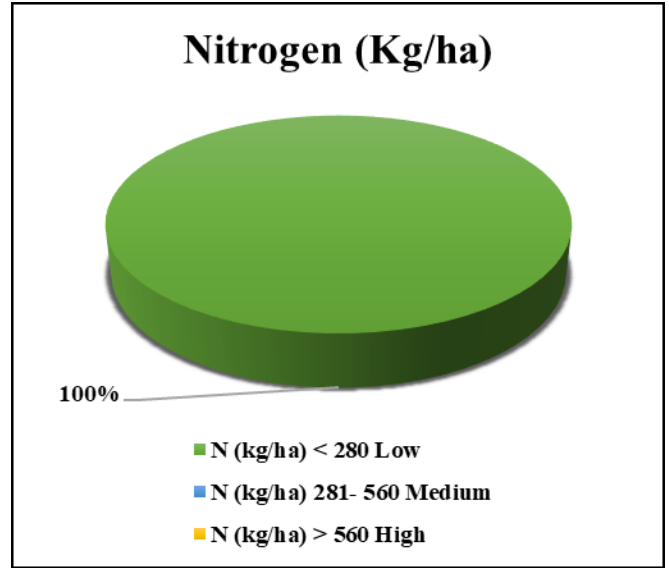

Fig: 6 Graphical representation of Nitrogen

3.5 Phosphorous, $\mathbf{P}(\mathrm{Kg} / \mathbf{h a})$ : The average Phosphorous content was reported to be $\mathbf{6 . 9} \pm \mathbf{2 . 2}$, which indicates Phosphorous is very low. Out of 3000 samples $97.5 \%$ (2925) had less than $12.5 \mathrm{~kg} / \mathrm{ha}$ Phosphorous and the rest $2.5 \%$ (75) has medium Phosphorous i.e., in the range 12.5-25 kg/ha (Fig: 7).

3.6 Potassium, K (Kg/ha): The average Potassium content was reported to be $\mathbf{5 5 3 . 4} \pm \mathbf{1 5 5}$, which indicates Potassium is very high. Out of 3000 samples, Potassium content was high in $95.17 \%$ (2855) farm fields, $4.66 \%$ (140) farms have Potassium, in the range 135-335, and only $0.17 \%$ (5) farms were which have low potassium content (Fig: 8). 


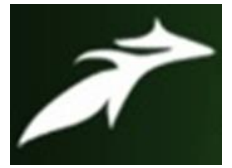

Anil Kanaujia et al, International Journal of Advances in Agricultural Science and Technology,

Vol.8 Issue.6, June-2021, pg. 1-9

ISSN: 2348-1358

Impact Factor: 6.057

NAAS Rating: 3.77

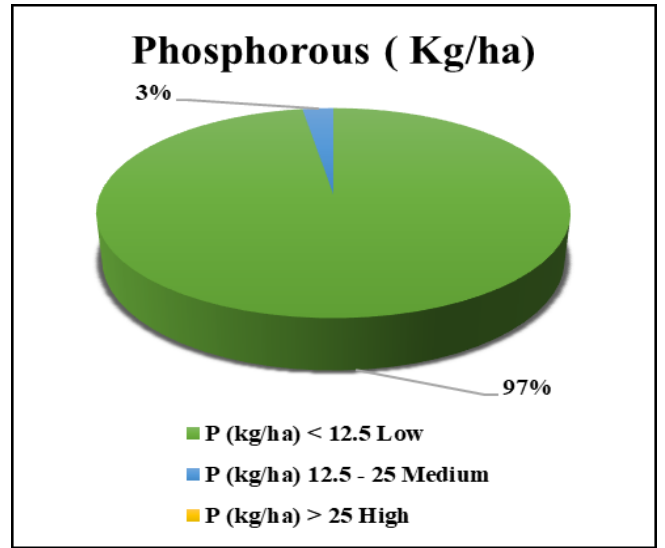

Fig: 7 Graphical representation of Phosphorous

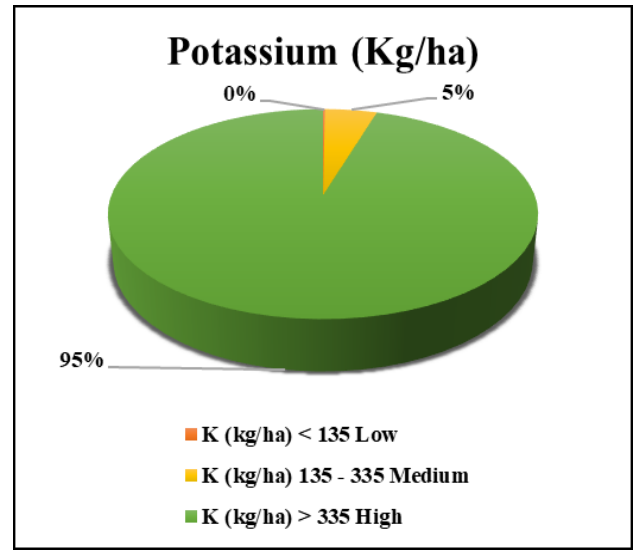

Fig: 8 Graphical representation of Potassium

3.7 Sulphur, $\mathbf{S}$ (ppm): The average Sulphur content is $\mathbf{7 1 . 5} \pm \mathbf{1 3}$, which indicates Sulphur is high. Sulphur is high in all the 3000 samples which were analyzed (Fig: 9).

3.8 Zinc, $\mathbf{Z n}$ (ppm): The average Zinc content is $\mathbf{1 . 4 8 \pm 0 . 4}$, which indicates Zinc is very high. it was reported that $79.27 \%$ (2378) of samples have high Zinc content i.e. $>1.2$ ppm, however $16.63 \%$ (499) samples have Zinc in the range of $0.6-1.2 \mathrm{ppm}$ and $4.1 \%$ samples have Zinc less than $0.6 \mathrm{ppm}$, hence fall in the low category (Fig: 10).

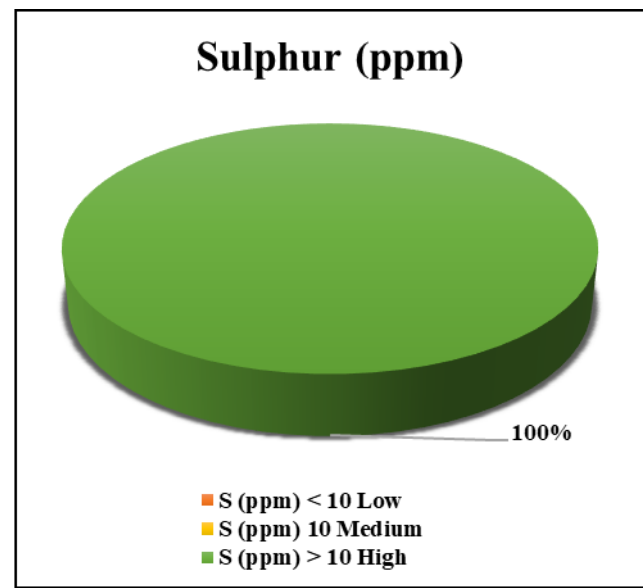

Fig: 9 Graphical representation of Sulphur

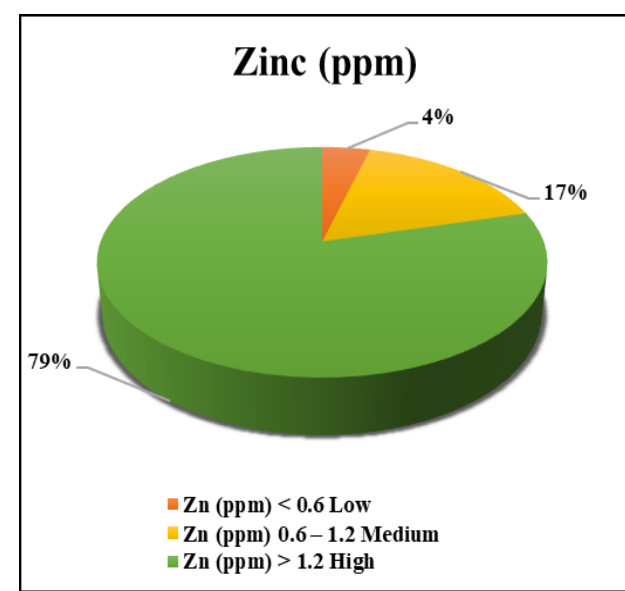

Fig: 10 Graphical representation of Zinc

3.9 Iron, Fe (ppm): The average Iron Content is 5.9 $\mathbf{2}$, which indicates Fe Content fall in range 4.5-9.0 ppm and is relatively adequate. 64.65\% (1939) soil samples have Iron content in the range 4.5-9.0 ppm, followed by $21.87 \%$ (656) have Fe less than 4.5 and $13.5 \%$ (405) samples have Iron content higher than 9.0 (Fig: 11).

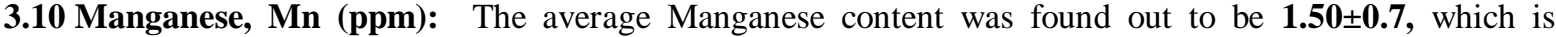
relatively low. In $60.23 \%$ (1807) samples Manganese was low i.e less than 3.5 ppm. In $25.87 \%(776)$ 


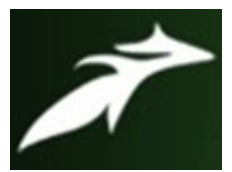

Anil Kanaujia et al, International Journal of Advances in Agricultural Science and Technology,

Vol.8 Issue.6, June-2021, pg. 1-9

ISSN: 2348-1358

Impact Factor: 6.057

NAAS Rating: 3.77

samples, Manganese was in the optimum range i.e., 3.5-7.0 ppm followed by $13.9 \%$ (417) samples which have high Mn, i.e. more than 7.0 ppm (Fig: 12).

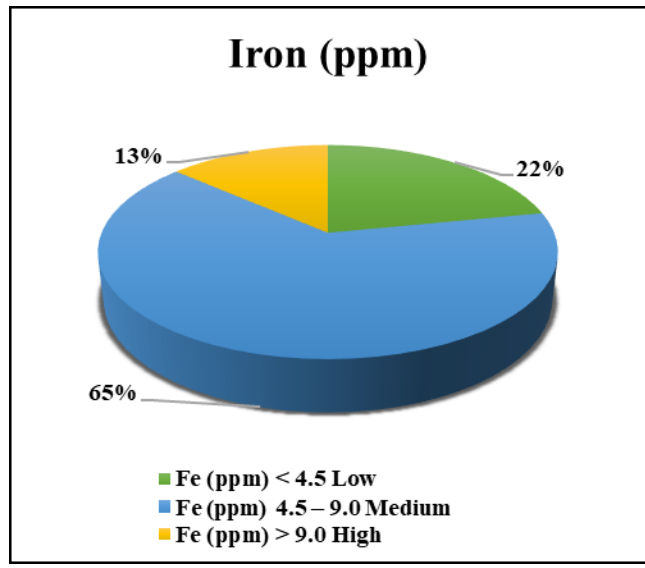

Fig: 11 Graphical representation of Iron

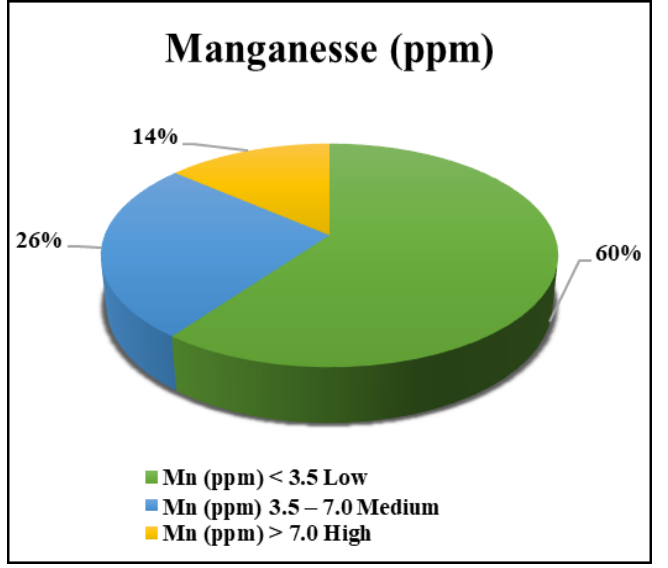

Fig: 12 Graphical representation of Manganese

3.11 Copper, $\mathbf{C u}(\mathbf{p p m})$ : The average Copper content was recorded as $\mathbf{3 . 7} \pm \mathbf{2 . 4}$, which is very high. In $98.13 \%$ (2944) samples Copper was high i.e., more than 0.4ppm, in $1.8 \%$ (54) samples Copper was in the optimum range i.e., 0.2-0.4 ppm and in rest 0.07\% (2) the Copper content was low (Fig: 13).

3.12 Boron, B (ppm): The average Boron content was recorded as $\mathbf{0 . 8} \pm \mathbf{0 . 0 4}$, which is under optimum range i.e., 0.5-1.0ppm. out of 3000 samples $52.50 \%$ (1575) samples have adequate Boron content, followed by $25.33 \%$ (760) samples which have low Boron content i.e., less than $0.5 \mathrm{ppm}$. the remaining $22.17 \%$ (665) samples have Boron content higher than 10ppm (Fig: 14).

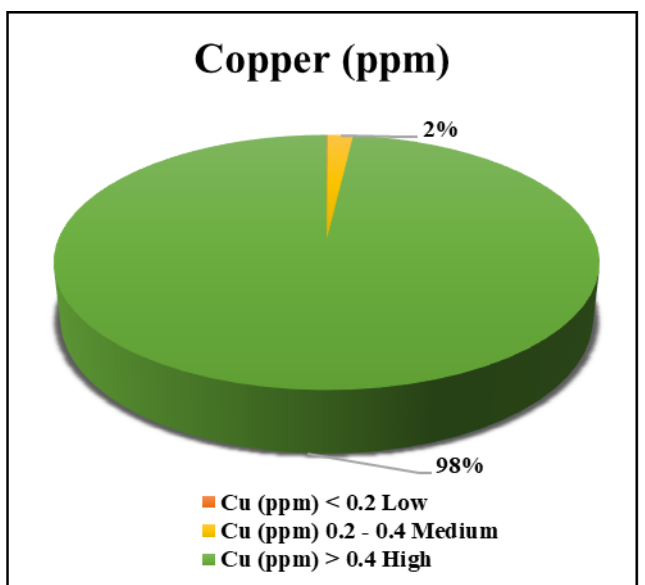

Fig: 13 Graphical representation of Copper

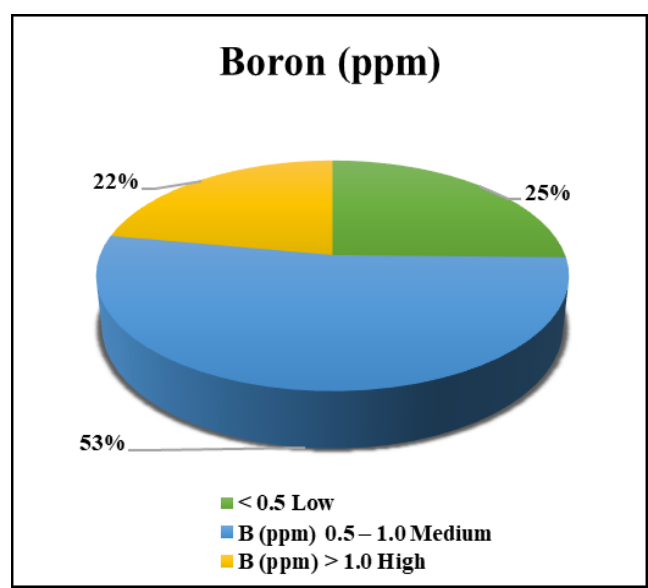

Fig: 14 Graphical representation of Boron

Based on the inputs on fertility parameters, information on suitable fertilizers with optimal dosage was automatically calculated and printed on each and every Soil Health Card for six major crops of the region. It came to the fore that $78.0 \%$ of soil samples are deficient in organic carbon. Organization shall propose Govt. of Haryana to undertake a demonstration project on replenishment of the organic carbon content of 100 acres 


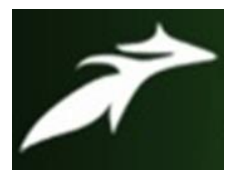

Anil Kanaujia et al, International Journal of Advances in Agricultural Science and Technology,

Vol.8 Issue.6, June-2021, pg. 1-9

ISSN: 2348-1358

Impact Factor: 6.057

NAAS Rating: 3.77

of land using 3-4 applications of vermicompost (@2.0 ton/ acre/dose)/ year, which is a very good source of said parameter and microorganisms, reanalyzing the soil samples at regular intervals for a period of 18 months to confirm optimal level of Organic carbon and microorganism status for better crops growth and high productivity.

\section{CONCLUSION}

Under Govt. of Haryana sanctioned Soil Health Card project to carry out fertility status study of 3000 acres of land of village Baroda Mor, block Mundlana, tehsil Gohana, Sonipat, Haryana and distribute the cards well before the harvesting of Rabi crop. Team ARF systematically carried out the registration of farmers, collection of 3000 soil samples, analysis for 12 parameters. Soil of village Baroda Mor, Sonepat is found to be moderately alkaline, majorly deficient in Organic Carbon, Nitrogen and Phosphorus. Potassium and Sulphur are in high quantity whereas secondary nutrients Zinc, Copper, Boron, Iron are found to be in range of medium to high where as Manganese is low as per the Govt. specifications. Replenishment with vermicompost (@2.0 ton/ acre/dose)/ year to increase the organic carbon content of soil may be one of the best options for enhanced available nutrients absorption, better crops growth and high productivity.

\section{REFERENCES}

[1]. John Idowu, Rajan Ghimire, Robert Flynn, and Amy Ganguli, 2019, Soil Health-Importance, Assessment, and Management, College Of Agricultural, Consumer And Environmental Sciences, Cooperative Extension Service, Circular 694B

[2]. Kanaujia, A., Banerjee, S., Rai, D. Soil health index- an initiative of ARF for the farmers of district Sonipat, Haryana, International Journal of Global Science Research, 2020, 7(2), 1376 - 1381.

[3]. Pusa STFR Meter, User instruction manual.

\section{A Brief Author Biography}

Dr. Anil Kanaujia - Skilled Scientist with $25+$ years of experience in natural product chemistry and medicinal chemistry based new drug discovery research, process chemistry, research on food safety, isolation $\&$ characterization of molecules from medicinal plants using Flash chromatography, 1H, 13C and 2D NMR spectroscopic techniques; commercialization of standardized herbal extracts, standardization of polyherbal formulations, analytical research \& method development and validation using HPLC-PDA, HPTLC, AAS, UV VIS spectrophotometer etc. techniques. Currently working with the AYURVET RESEARCH FOUNDATION, Sonepat, Haryana, as Head- R\&D, managing and providing the guidance on innovative research projects to the team of professionals. Credited with 14 patents (10 US, 1 Chinese, 3 Indian), published 27 research articles in peer reviewed international and national journals.

Ms. Samanwita Banerjee - Skilled and educated professional with M.Sc. microbiology from Bangalore University in the year 2010. Having more than 8 years of experience of performing various microbiological and chemical testing, Research and Development in the areas of research on food safety, analytical research, feeds analysis, Milk analysis, quantification of active ingredient in medicinal plant. Having an experience on Instrumentation such as ELISA technique, UV spectroscopy, Flame photometer, IR moisture balance, STFR machine, etc. Published 6 research articles in peer reviewed international and national journals. 


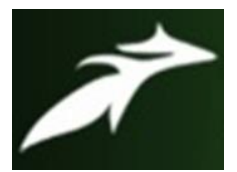

Anil Kanaujia et al, International Journal of Advances in Agricultural Science and Technology,

Vol.8 Issue.6, June-2021, pg. 1-9

ISSN: 2348-1358

Impact Factor: 6.057

NAAS Rating: 3.77

Ms. Suruchi Malik- An enthusiastic and fervid professional in microbiology. Completed Post-graduation in Microbiology from CCS University, Meerut in 2020 \& PG diploma in food safety \& quality management from IGNOU, Delhi. Have 1.5 years of experience of analytical testing in Chemical \& microbiological analysis in Food, Feed, Water, Milk \& Milk products. Involved in Research \& development activities for food safety \& sustainable development.

Ms. Kirti Sharma- A passionate, creative \& enthusiastic technologist, post graduated from Thapar Institute of Engineering \& Technology, Patiala (batch 2018-2020) and graduated from GGDSD college, Chandigarh, have an experience of seven months in chemical testing in quantitative assessment of medicinal plants and animal feed, trained in analysis in field of food quality and pharmaceuticals and also involved in research \& development activities of one health.

Mr. Deepak Tyagi - Mr. Deepak Tyagi, hold bachelor degree in Commerce and master degree in business management from Sikkim Manipal University. Experienced professional with more than 10 years of experience in data management, statistical data, analysis of data, etc. Currently associated with Ayurvet research foundation as executive handling the data analysis section.

Dr. Deepti Rai - A Techno-commercial person with 16 years of diverse experience in interdisciplinary Research \& Development. Qualified Ph.D (Horticulture) from GB Pant University \& Agriculture and Technology, Presently serving Ayurvet Research Foundation, Ghaziabad as Head : Hydroponic -Research \& Coordinator for Collaborative research Projects with ICAR University/ Instititure through MOUS. A selfmotivated professional with keen analytical abilities \& in depth understanding of the economics and dynamics of Agriculture \& Biotechonolgy. Looking for opportunity in an interdisciplinary research\& application, where I could use my experience and qualification for the betterment of science and masses. In nutshell, I am a Scientist with Business Acumen.

Ms. Abha Saxena - Award Winning ( Young achiever -2020) and dedicated Executive - Research and Development, serving Ayurvet Research Foundation, Ghaziabad . 3 years of experience in Hydroponics, Biotechnology, waste management, and Molecular Biology .Educated to Masters in Biotechnology from Banasthali Vidhyapith, Rajasthan and Bachelors in Life Sciences fro University of Delhi. Published author of $15+$ manuscripts appeared in peer reviewed journals. Certified Industrial Biotechnologist from University of Manchester, England. Techno-commercial person leading experimental trials and experience in product development and examination. Knowledge of processes pertaining to Patent filing and Regulatory Compliance. Certified Digital Marketer. 